\section{Penguin dispersal after fledging}

SIR - Emperor penguins have several attributes that place them in high regard with biologists and others visiting Antarctica. The Ross Sea birds are of special interest because they occur in the last marine frontier that has not been exploited by humans, where biologists have the unique opportunity to do population studies before the pristine conditions are disrupted. Also, the geography of this sea provides a safe haven compared with areas on the outer perimeter of the continent. Two of our purposes in studying these birds were to determine: (1) if the initial foraging range of juveniles overlapped with premoult feeding adults, potentially resulting in competition; and (2) if the emperor penguin is to be an effective resource

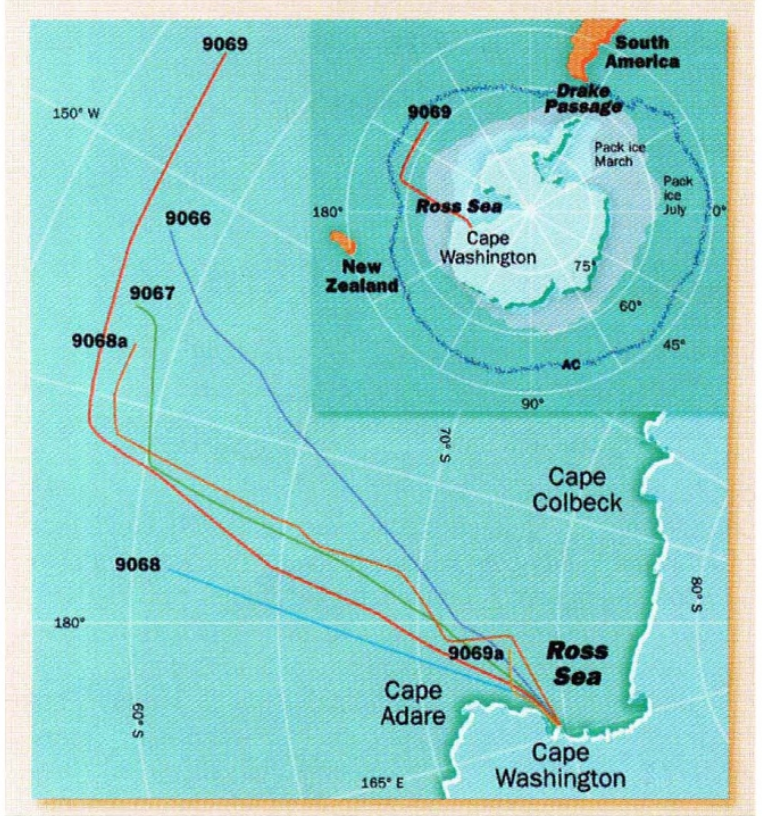

Routes of emperor penguin juveniles obtained from satellite transmitters (Telonics, ST-10; mass $120 \mathrm{~g}$ ) attached by glue (Loctite 422) to the lower part of the back. From 15 to 19 December 1994 (9068a, 9069a) and 1995 (9066, 9067, $9068,9069)$, the birds ranging in body mass from 10.9 to $14.2 \mathrm{~kg}$ (mean $12.8 \mathrm{~kg} \pm 1.3$ s.d.)(AND-FW $150 \mathrm{~kg} \pm 20 \mathrm{~g}$, platform scale) were captured and released near the ice edge of Cape Washington $\left(74^{\circ} 32^{\prime} \mathrm{S} ; 165^{\circ} 22^{\prime} \mathrm{E}\right)$. Within a few hours of release, the birds entered the water. Positions were monitored from 4 January 1995 (9069a) to 6 March 1996 (9069). During this time all birds had reached positions far enough north to be in the Westwind Drift ${ }^{8}$. We expected transmissions to continue during June, but the lack of signal suggests that the birds remained in water north of the pack ice. (Transmitter position on the bird prevents transmissions while the birds are swimming.) The pack-ice edge in this sector of the Southern Ocean based on satellite images was well south of $66^{\circ} \mathrm{S}$ by 7 December 1995. In the previous year, the pack ice edge on 15 June 1994 determined by direct observation by GLK from a US Air Force $\mathrm{KC}-10$ flying at $11,000 \mathrm{~m}$ was at $61^{\circ} \mathrm{S}$. General boundaries of the Antarctic Convergence and winter and summer pack-ice edges vary from year to year. Rendering of the inset is based on various figures ${ }^{7,8}$. Antarctic Convergence (AC, dark blue line); pack-ice edges in July and March 1987 are shown. habitat of emperor penguins breeding in the Ross Sea is much larger than that sea alone. The extensive travel of the juveniles implies that Ross Sea populations of this species are, at least during one crucial part of their life, exposed to some of the same risks as more northern conspecifics. Of particular concern is the possible impact of commercial fishing around the Antarctic continent. We suggest that if adequate protection is to be given to this species, and perhaps to other Antarctic species as well, the dispersal patterns of the young must be determined. As written, the Antarctic Treaty and the Convention on Antarctic Marine Living Resources extend only to the 60th parallel in this region of Antarctica ${ }^{7}$. These new data suggest that the 60th parallel is probably too limiting to protect adequately even the most familiar symbol of Antarctic wildlife, the emperor penguin.

\section{Gerald L. Kooyman \\ Tory G. Kooyman \\ Markus Horning}

\section{Carsten A. Kooyman}

Scripps Institution of Oceanography, University of California, San Diego,

La Jolla, California 92093-0204, USA e-mail: gkooyman@ucsd.edu

\footnotetext{
1. Ancel, A. et al. Nature 360, 336-339 (1992).

2. Kooyman, G. L. Croll, D., Stone, S. \& Smith, S. Polar Record 26, 103-108 (1990).

Record 26, 103-108 (1990). (Oxford Univ. Press, 1995)

4. Prévost, J. Ecologie du Manchot Empereur Exp. Pol. Franc. Publ. No. 222 (Hermann, Paris, 1961).

5. Isenmann, P. L'Oiseau et la Revue Francaise d'Ornithologie 41, 9-64 (1971).

6. Jouventin, P. La Terre et la Vie $25,510-586$ (1971).

7. Knox, G. A. The Biology of the Southern Ocean: Studies in Polar Research (Cambridge Univ. Press, 1994).

8. Gloersen, P. et at. NASA SP-511 (Washington DC, 1992).
}

\section{Optical fibres in an Antarctic sponge}

SIR - The skeleton of demosponges and hexactinellids is generally composed of spicules consisting of amorphous hydrated silica (opal) ${ }^{1}$ laid out around a proteic axial filament ${ }^{2}$. Spicules constitute a mechanical support and act as deterrents to predators ${ }^{3}$. The presence of a filamentous green alga (Ostreobium) closely associated with the spicule bundles of a demosponge (Tethya seychellensis) suggested to us that light energy might reach the inside of the sponge body via siliceous spicules ${ }^{4}$. Such a natural optical-fibre system could influence sponge/symbiont interactions $^{5-7}$ and wider aspects of sponge biology ${ }^{8}$.

We showed that siliceous spicules can act as optical fibres by using long spicules of an Antarctic hexactinellid (>10 cm long), whose large size allows easier handling of the very small demosponge 